\title{
Contadores de histórias em $A$ República dos Sonhos e em Vozes do Deserto, de Nélida Piñon
}

\author{
Lúcia Regina Lucas Rosa*
}

\begin{abstract}
Resumo: O presente artigo visa evidenciar as marcas Abstract: The present article aims to evidenciate the de oralidade e atuação de contadores de histórias nos marks of orality and the performance of storytellers in romances A República dos Sonhos e Vozes do Deserto, the novels The Republic of Dreams (A República dos de Nélida Piñon. Ambas obras literárias priorizam a Sonhos) and Voices of the Desert (Vozes do Deserto), narrativa do ponto de vista da influência de um by Nélida Piñon. Both literary compositions prioritize narrador-contador que, com isso, domina a vida das the narrative of the point of view of the influence of the demais personagens. Mesmo publicados em épocas narrator-storyteller who, with this, dominates the life of diferentes, os romances dão conta da discussão de the other characters. Despite being published at perpetuação de clãs familiares e de costumes de different times, the novels denote the perpetuation of determinados grupos sociais por meio de histórias familiar clans and customs of certain social groups criadas e outras lembradas. through stories that are either remembered or invented.
\end{abstract}

Palavras-chave: histórias; encanto; sonho; morte. Keywords: stories; enchantment; dream; death.

"Um país empobrece depressa quando lhe roubam suas histórias."

Os romances A República dos Sonhos e Vozes do Deserto, de Nélida Piñon, publicados em 1984 e 2004, respectivamente, identificados a partir de agora pelas suas iniciais RS e VD, possuem marcante presença da contação de histórias. Ambas narrativas são conduzidas por um personagem-contador que cria um universo à parte e isola-se dos demais personagens em um mundo recriado. Embora tenham diferentes objetivos para tais recriações, os contadores aqui em análise primam pela constituição de fatos com seus detalhes ricos e encantadores.

Madruga é o personagem central em RS, ele vem da Galícia para o Brasil e traz em sua bagagem apenas as vivências e a grande vontade de vencer. Ao melhorar sua situação econômica, após alguns anos, volta a sua terra natal e casa-se com Eulália. No Brasil, então, estabelece-se definitivamente e vê sua família aumentar com a chegada dos filhos e da neta

\footnotetext{
* Doutoranda da UFRGS e prof. Unilasalle.
} 
Breta. Quando criança, Madruga sempre acompanhava seu avô e dele ouvia histórias e ensinamentos de vida:

Sob influência do avô Xan, Madruga zelava pelas lendas galegas. Temia que, por descuido seu, algumas se perdessem. Quando formavam, em conjunto, um repertório tão vasto, que escapava ao controle do próprio Xan. Talvez por esta razão, pediu Madruga ao avô nesta última semana, que acelerasse o seu tom narrativo, a fim de acumular um número maior de enredos. (...) Só que às vezes, esquecido da função de rapsodo, deblaterava-se contra os castelhanos, acusandoos de espoliar Galícia. (...)

- Eles furtaram justamente aquelas histórias que nós engendramos para atrair o sono e tornar suportável o convívio humano, disse Xan ao neto. (PIÑON, 2005 p. 80-1)

- Havia menos leis, meu neto. E o próprio homem organizava seu código de honra. Por isso, ao encontrar no descampado um outro homem de código igual, viajavam juntos, na condição de cúmplices. Desse modo, os países e os grupos iam formando alianças. O mesmo ocorrendo com as línguas e as histórias. As histórias que eu sempre conto por pedaços. (idem, p. 117)

Ele jamais escondera seu amor pelo neto. O único a ouvir-lhe certas histórias saídas diretamente dos seus lábios. Aquelas histórias que cobriam episódios recentes, mas que se ocupavam também do passado. E tudo pelo prazer de reter Madruga ao seu lado. (idem, p. 356)

Assim, Madruga cresceu encantado com a sabedoria do avô Xan. A distância dos pais e de sua terra fazia-o remeter-se à infância e, fatalmente, às histórias e à aprendizagem sobre o sonho. Em parte, foi esta convivência que o fizera decidir-se morar no Brasil. Ele realizava, assim, o sonho de seu tio, de seu avô e dele mesmo, reunia as qualidades dos parentes e assumia para si o compromisso de fazer o que eles não conseguiram. Quando ficava triste e com saudade, restava-lhe a lembrança do passado, de sua vida pacata e sonhadora:

A memória levava-o diretamente à Galícia, cenário da sua infância. Por onde se movia como um caçador de borboletas. Sem se esquecer porém de recorrer ao avô Xan. Era ele o primeiro a fazê-lo voar, a lhe propor a aventura. (PIÑON, 2005, p. 8)

Em VD, a autora reconta a saga árabe de Scherezade, "vítima voluntária", que precisa contar histórias todas as noites para que o Califa não ordene sua morte e também para que outras mulheres não sejam mais sacrificadas. Ela assume para si a situação de perigo e passa a viver atormentada pela necessidade de aperfeiçoar seus relatos, uma vez que recebera educação esmerada e sempre fora dedicada ao prazer do conhecimento:

Scherezade não teme a morte. Não acredita que o poder do mundo, representado pelo Califa, a quem o pai serve, decrete por meio de sua morte o extermínio da sua imaginação. (...) Há muito viúvo, o Vizir mantinha-se fiel à memória da esposa, resistindo a contrair novo matrimônio, ainda que o Califa o estimulasse. Em casa, porém, aturdido com o talento de Scherezade, facilitava-lhe esmerada educação. Os mestres de Bagdá, convocados para esta missão, amanheciam diariamente no palácio, só deixando Scherezade ao anoitecer. Munidos de toda sorte de conhecimentos, mesmo dos gregos clássicos, alguns dos sábios provinham da escola de tradutores, outros, associados às madrasas, aperfeiçoavam-se nos estudos exegéticos do Corão. (...) Enquanto Dinazarda era negligente nos estudos, Scherezade cobrava dos mestres as chaves com as quais abrir as portas da percepção e da sabedoria. Nada lhe satisfazia a ambição intelectual, para perplexidade dos professores. (PIÑON, 2006, p. 7 e 112) 
Além da dedicação aos estudos, Scherezade também era fascinada pelas histórias que sua ama lhe contava. Pelo fato da mãe ter morrido logo após o seu nascimento, ela não conviveu como as irmãs, repletas de cuidados maternos, porém, sua ama, Fátima, supriu esta carência encantando-lhe os dias com suas histórias. Mais que as irmãs, ela destacava-se na arte da narrativa com perfeição: "Sobre ela paira a auréola provinda da arte de contadora" (PIÑON, 2005, p. 36). Respeitada na família pelo ofício da contação de histórias, Scherezade se entrega resignada à aventura/desventura de salvar as mulheres árabes da vingança daquele homem tão temido pelo povo. Como as grandes mulheres da humanidade, encarna também o mito de Penélope ${ }^{1}$ à medida que tece com as palavras:

Com o tear e o algodão entre os dedos, ela ia afinando os fios para fazer com eles, ao final, um tipo de manta capaz de proteger os ouvintes do frio das noites no deserto. Scherezade, porém, afligia-se sob a pressão dos méritos que lhe eram atribuídos. Pouco afeita às homenagens, recusava ser a tecelã que Fátima lhe atribuía. (PIÑON, 2006, p. 37)

Grande parte destas narrativas ocupam-se em descrever os sonhos. Em RS, vários homens daquele povoado desejam ir para o Brasil, depois de crescer na própria Galícia, ou ainda pequenos, outras vezes, o sonho se resume apenas em meramente viver aventuras. Em VD, o personagem encerra em si o sonho de várias mulheres, tanto o de ser a escolhida pelo Califa, quanto o de ser a grande vendedora de ilusões e fantasias; e também a própria Scherezade gostaria ardentemente de encontrar o seu príncipe encantado e rever Fátima morando feliz e longe de Bagdá. Para BACHELARD (1988), o sonho é imprescindível para que o homem se abra para uma nova vida; é no sonho ou no devaneio do poeta que o mundo surge pela imaginação. Para FRYE (2000), a imaginação ganha maior força nas artes, no amor e na religião; na obra literária, é preciso recuperar o tempo e reconstruir o espaço; há uma necessidade de manter a seqüência narrativa, de evidenciar a totalidade, o fechamento. Para tanto, nas obras em análise, os personagens se fundem e se complementam: tanto Madruga e Venâncio, quanto seu avô e Salvador viveram o delírio de uma vida cheia de emoções e novidades; Scherezade perpetua sua ama que era exímia contadora de histórias e Dinazara, sua irmã, aprende a contar histórias o suficiente para substituí-la na sua ausência. Se o objetivo do devaneio é abarcar o todo, numa possibilidade de integração com o cosmos, esses personagens o fazem com maestria, visto que chegavam a criar um mundo à parte, negando-se

\footnotetext{
${ }^{1}$ Penélope = personagem consagrada na literatura universal. Mencionamos aqui a referência à criação de Homero, na Odisséia: representa a fidelidade conjugal, na medida em que destece durante o dia a mortalha do sogro tecida à noite, afastando, assim, os pretendentes ao trono de Ítaca por três anos - pois diante do surgimento de muitos pretendentes que acreditavam que o marido, Ulisses, não voltaria vivo da guerra, ela só decidiria com quem se casar após terminar aquele artesanato. Segundo Brandão, Penélope foi uma das únicas esposas a esperar pelo cônjuge por vinte anos. [BERND (org.), 2007, p. 512].
} 
a participar das convenções da sociedade a qual pertenciam. Venâncio e Salvador, inclusive, eram por vezes mal recebidos pelos familiares dos seus amigos. Eles jogavam-se de corpo e alma em suas crenças e buscavam seguidores, exatamente como apregoa BACHELARD (1988):

O sonhador, em seu devaneio sem limite nem reserva, se entrega de corpo e alma à imagem que acaba de encantá-lo.(...) uma única imagem cósmica lhe proporciona uma unidade de devaneio, uma unidade de mundo. (...) Desde a abertura do mundo por uma imagem, o sonhador de mundo habita o mundo que acaba de lhe ser oferecido. De uma imagem isolada pode nascer um universo. (BACHELARD, 1988, p. 167)

Por isso, o sonhador passa a ser incompreendido; à medida que cria e habita o mundo imaginado, outras pessoas - que não participam do mesmo sonho - vêem-no como alguém fora da realidade e impossível de ser alcançado. Venâncio chega até mesmo a ser internado em um hospício e só recebe apoio de Madruga e de Eulália; ele por compreendê-lo, e ela, por sentir dó de um amigo e admirador. Da mesma forma, Scherezade vai morar no deserto sem sequer deixar o endereço para a família.

A vida de Madruga arrasta-se sob influência das histórias, lendas e a fusão dos dois países em sua memória, Espanha e Brasil: “de tanto interligar as histórias dos dois países, já não mais as distinguia" (PIÑON, 2005, p. 99). Como num conto épico, cobra-se a todo tempo a luta para "vencer a América", um mito para o povo da Galícia. A promessa de vida melhor e enriquecimento impulsionava-o a trabalhar e a reconstruir a história de sua família, muitas vezes, mesclada com lendas, heróis verdadeiros e outros tantos inventados. Num misto de fantasia e realidade, tenta fazer com que seus filhos participem de seus sonhos e devaneios, o que raramente ocorria. Outro atrativo para ele também era o fato de que julgavam que a vida na América era feita de grande desordem e que, assim, cada um poderia construí-la como melhor lhe aprouvesse, inclusive com oportunidades para juntar grandes fortunas. Movidos por idéias arraigadas de sua cultura, muitos ditos são repetidos ao longo da narrativa, como: “Os nascimentos em geral previam a eminente partida dos mais velhos"( PIÑON, 2005, p. 103). Crenças como essa revelam o quanto aqueles que transgrediam os costumes chamavam a atenção e até mesmo eram desconsiderados como homens sérios, principalmente aqueles dedicados a contar histórias e lendas. Embora muitos gostassem de ouvi-los, não lhes davam crédito quando se tratava de uma situação da realidade. Madruga, mesmo conhecendo várias histórias, sentia necessidade de ouvir outras tantas contadas pelos mais velhos. Tinha medo de perder a ligação com os antepassados e assim, as próprias histórias não terem sentido, precisava ser o elo entre as gerações, o que só seria possível pela junção dessas histórias, principalmente as que foram contadas pelo avô: 
Sob influência do avô Xan, Madruga intensificara sua perseguição aos velhos, visando a ouvir deles, enquanto ainda tinham dentes e memória,o relato das histórias circunscritas, em geral, à Galícia. (...) A pressa de Madruga, no entanto, despertava simpatia. Sobretudo por ser o neto de Xan, um mestre na insuperável arte de contar histórias populares. Bastava-lhe abrir a boca, da qual sempre pendia o cigarro de palha, para instaurar-se grave silêncio. Por isso se estranhando que, tendo à mão um narrador assim exímio, Madruga precisasse extorquir dos vizinhos as histórias que tinha de sobra em casa.

Xan entrelaçava os fatos e as lendas com linguagem colorida e vivaz. E sempre que precisava enxertar novos elementos ao relato, abria parênteses, sem perder por isso o fio da meada. Diante, porém, da ansiedade alheia pelo desfecho, jamais acelerou o relato. Condenava a quem o forçasse a abreviar a história.

- Se uma história exige um ano até ser contada, seria um crime amputar-lhe a beleza e a imaginação. Quem não sabe ouvir, vá bater em outra freguesia. Ou passe a viver sem elas. (...) Pedia-lhes, no entanto, licença, e com autoridade outorgada por todos, retomava o enredo alheio como se desde o início fosse seu, recheando-o, de imediato, com detalhes surpreendentes, que só ganhavam relevância ao final da história. Tal proeza às vezes merecendo aplausos. (PIÑON, 2005, p. 111-2)

Pela citação acima, percebe-se a importância dada, nesta obra, à tradição e às pessoas mais velhas. A figura do neto, criança, ouvindo o avô e seus amigos, reforça a importância da contação de histórias para a cultura de um povo. Importância mais reforçada ainda nas páginas seguintes, na qual o neto discute com o professor após este desistir de disputar a atenção de Madruga com o avô. Ao argumento de que as histórias orais se perderiam com o tempo por não estarem escritas, Madruga prontamente rebate alegando que o avô conhecia histórias já há muito tempo e que ele, provavelmente, seria o cultuador dessa tradição e que o avô, embora apenas "falasse" suas histórias, nem por isso desvalorizava os livros.

Já Scherezade ficava presa no castelo, não tinha permissão para se afastar, muito menos para passar um dia fora. E o próprio Califa acabou por ficar mais tempo em casa e delegando suas tarefas bélicas para outros - sequer a honra de guerrear o atraía, apenas as histórias ali ouvidas todas as noites o prendiam. $\mathrm{O}$ ato sexual, para ele, era apenas a preparação para ouvir mais e mais histórias, uma mera obrigação, pois o prazer advinha mesmo do encantamento narrado. Também aqui, a tradição do aprender a contar histórias é valorizada pelas figuras da tradição oral:

A mãe, prestes a exalar o último suspiro, tendo Fátima ao lado, esforça-se por sorrir. Comoviaa que os relatos iniciais daquela filha abarcassem figuras lendárias do deserto, das mesquitas, dos mercados islâmicos. Como se não lhe bastando contar com os membros da casa para a formação de seus enredos, precocemente preparava-se para lidar com a carne alheia que sofria, sonhava, forjava mentiras, e não tinha nomes.

Mal aprendera a andar, e despontaram nela a memória incorruptível e a atração pelo inefável, já ao seu alcance. Sob os cuidados de Fátima, ela desenterrava, desenvolta, mortos e figuras emblemáticas, acasalava adversários e amantes, traduzia o âmago do amor. (PIÑON, 2006, p. 38)

... rechaçando ser heroína de si mesma ou de suas histórias, prefere emprestar a príncipes e plebeus, escolhidos a esmo, as palavras apaixonadas que intensificam a vulva de Zoneida e o falo de Simbad. 
O certo é que não pretende fomentar o ardor narrativo com sentimentos amargos. Ou fazer de seus personagens réplicas de si mesma. Não se lamuria usando o próprio nome, para isto domestica sua dor, torna-a inexpessiva. (...) Para ter em mira que suas antecessoras, noivas como ela, confiantes na própria beleza, esperaram do monarca consideração. (PIÑON, 2006, p. 42)

Nélida Piñon, ao narrar as histórias destes romances, valoriza bastante a descrição de como as histórias são relatadas pelos personagens. Os detalhes de postura, entonação de voz e gestos ambientalizam e situam o leitor de tal forma que chegam a existir várias histórias dentro da história central dos livros. Porém, elas são apenas mencionadas e não contadas e são tantas que, se fossem relatadas, a obra teria muitos e muitos volumes. Além disso, a história contada em si não é o mais importante, pois o essencial é revelar personagens que cultuam a tradição oral para que assim, haja crédito junto ao leitor quanto à força de uma narrativa que remonta às tradições de um povo, principalmente a literatura popular oral. Nela, a autora caracteriza aspectos essenciais que aproximam alguns personagens entre si durante a contação de histórias, que é a performance. Tal descrição dá conta de como as histórias mantêm-se vivas com o passar dos tempos e por que alguns personagens se destacam em tal ato. Essas características do personagem-contador vai ao encontro daquilo que já foi mencionado por Paul Zumthor (2000, p. 35-36): “... performance implica competência. (...) É um saber que implica e comanda uma presença e uma conduta (...) uma ordem de valores encarnada em um corpo vivo". O autor também nos fala em "hábitos receptivos", tudo gira em torno do objetivo de "gerar prazer" porque assim prende o ouvinte para a história do momento e o faz receptivo para outras em outros momentos, ocasionando encontros seguidos e garantindo a vivacidade das histórias e dos contadores. A performance cria regras que são, constantemente, recriadas, importa o corpo como forma de comunicação e o espaço como ambientação favorável à audição. RICOEUR (1997) enfatiza a importância da performance como um cruzamento de várias perspectivas e sendo importante para entender o ato de narrar.

Para contar histórias, a performance vinha naturalmente, não havia muita preparação, era uma espécie de dom herdado de algum parente. Assim, Xan ressentia-se muito por nunca ter saído de Sobreira, na Galícia. Seu sonho era ir para a América e voltar para poder contar muitas outras histórias, como também para confirmar histórias ouvidas de outras pessoas que haviam ido para o Brasil: "Como exibir a autoridade de um legítimo contador de histórias, se não vivesse ao menos um oitavo delas? “(PIÑN, 2005, p. 383)

Assim como Madruga tornou-se herdeiro de Xan, sua neta Breta também passou a ser sua herdeira. Herança aqui, especificamente, a contação de histórias. Então, a narrativa de $A$ República dos Sonhos (2005) pode ser dividida em duas partes: primeira, a transmissão de 
Xan para Madruga e segunda, a transmissão de Madruga para Breta. Porém esta divisão é apenas de leitura, uma vez que a obra possui vários feed-backs. Curiosamente, as gerações se sucedem de avô para neto e não de pai para filho; provavelmente porque as histórias ganham tanta força que uma geração não necessita criar novos contadores, pois os mais velhos se preservam com credibilidade para continuar com sua platéia e criar outras novas. Então, ao intercalar uma geração, dá tempo para criar, desde pequenos, novos contadores:

Não cesso de observá-lo, como herdeira de sua sólida gênese. (PIÑON, 2005, p. 118)

- Somos mentirosos de nascença, Breta. E fadados a verdades que nós mesmos não compreendemos. Como se nossas verdades saíssem da sucata, do ferro-velho. Somos assim habitantes de um cemitério de navios, revestidos de melancolia e ferrugem. Os únicos que se salvam desta oxidação são os artistas. Talvez porque iluminem parcialmente os nossos túneis, sem temor de enfrentar detritos, monstros, e formas estranhas sem nome, que Eulália chama de alma. (idem, p. 121)

Percebi então que só conheceria o Brasil de fato através daquela neta. (idem, p. 252)

E sempre que lhe pedia esclarecimento sobre um episódio duvidoso, Breta compensava-me inventando uma outra história. E isto com um tom inquiridor, parecido ao do avô Xan. (idem, p. 253)

Scherezade, desde pequena, já encanta a família com seu conhecimento e suas criações. Embora nunca tenha ouvido as histórias de sua mãe, herdara o dom naturalmente dela, aperfeiçoado por Fátima. É pela performance que ela deslumbra os espectadores e garante a atenção da platéia Assim, ganha créditos cada vez mais fortes e concretiza seu objetivo: tornar o Califa tão dependente a ponto de não mais executar a promessa de vitimar as mulheres com quem passa a noite:

... ela alça-se à categoria dos imitadores. Compõe, com facilidade, a personalidade de um barítono, recém-chegado a Bagdá, que ostentava volumosa pança.

Compenetrada, Scherezade copiava-lhes os tiques nervosos, as sucessivas desafinações, indiferente a que Dinazarda e Jasmine rissem, pedindo mais. (...) a voz... amplia suas ações, assume novas prerrogativas narrativas. Empresta a cada papel uma imprescindível compreensão. Como homem e mulher, ri, chora, vítima de um trampolim emocional. Como tal, ela fabula figuras lendárias do mundo árabe que irradiam voluptuosidade, exsudam olores, destilam secreções, desafiam gigantes e monarcas, todos com dimensão mágica. (PIÑON, 2006, p. 130-1)

Com o passar das gerações, nada muda quanto à forma de contar histórias no mundo oriental. Já no ocidente, há uma grande mudança. Breta continuaria a narrar as mesmas histórias do avô, porém ela o faz por escrito. Com Breta, encerra-se o ciclo de narrativas orais da família. Esta situação não agrada muito a Madruga, ele sabe que suas histórias não precisariam ser escritas e sim recontadas: "Ele limitou-se a comentar que, por força do meu ofício de escritora, tornara-me arrogante e manipuladora de palavras. Tinha os dicionários e o léxico a meu favor" (PIÑON, 2005, p. 274). Madruga percebe bem a falta de vida de suas histórias pelo fato de passarem a ser escritas, assim como BENJAMIN (1985) observa acerca 
do narrador como alguém que está distante de nós e afirma que "a arte de narrar está em vias de extinção" (idem, p. 197). E mais forte ainda é a afirmação de FOUCAULT (2006), que relaciona o poder e a verdade ao discurso, ele alerta sobre a intenção que há por trás de todo discurso: "o discurso não é simplesmente aquilo que traduz as lutas ou os sistemas de dominação, mas aquilo por que, pelo que se luta, o poder do qual nos queremos apoderar" (idem, p. 10). Nei Clara de Lima (2003), ao estudar narrativas orais, valoriza o tom de verdadeiro que há nelas, portanto, também enaltecendo a oralidade como veículo da emotividade e reflexo da sociedade local:

... todos os que me contaram histórias disseram que as ouviram dos mais velhos. Pertencentes ao repertório popular das localidades pesquisadas, elas enfeixam um grande número de imagens mentais e afetivas, segundo as quais os moradores interpretam a si próprios, o seu passado e a sociedade em que vivem. (PIÑON, 2003, p. 12)

Há, em vários momentos de RS, discussão entre os personagens sobre a literatura oral e a escrita. Madruga confessa-se não-leitor, igualando um de seus filhos a ele: “- É uma pena que lhe falte competência para uma carreira política de envergadura. Nunca o vejo com um livro na mão. Sua cultura é de jornal. Igual à minha. Além do mais, você parece uma borboleta adejando sem rumo" (PIÑON, 2005, p. 544). A autora usa um caso singular de poder da escrita, na Espanha, que é o banimento de ciganos, para evidenciar a importância da oralidade:

E pareciam ainda desprezar a escrita, que não cultivavam entre eles. Havia até a suspeita de que esses ciganos difundiam pelas aldeias a noção de que a civilização ocidental agonizava, tomada pelo sentimento da extinção,exatamente por se voltar à escrita. Enquanto que eles esquivaram-se dos registros da escritura; e nem por isso lhes faltou um rico e deslumbrante repertório. De fato, só lhes importava a narrativa oral, livre e cheia de improvisos. E que Madrid julgava inconsequiente e subversiva, por não lhes permitir o controle do pensamento. (PIÑON, 2005, p. 458-9)

No caso de VD, a escrita sequer é considerada para a realidade e para as histórias inventadas. Todo o conhecimento advém da oralidade e sua respectiva credibilidade: "As regras da vida não estão escritas. Cabe-lhe inventá-las a cada aurora" (PIÑON, 2006, p. 255). Aqui não é necessário argumentar acerca da importância da oralidade, isto é sabido e reconhecido por todos.

Já no outro romance em análise, Madruga, explicitamente, manifesta sua intenção de preservar o poder sobre a família. Quando elege Breta para seguir sua tarefa, exerce também o poder sobre seus filhos, relegando-os em favor da neta, tarefa prontamente aceita por ela. Breta, então, apropria-se da oralidade dos avôs-contadores para realizar sua tarefa. Madruga é quem tem o conhecimento de toda a história da família - as verdadeiras e as inventadas - e, 
como o pensamento oral tem outra estrutura, conforme HAVELOCK (1996), há um vai-evem de épocas, para recuperar a memória, os fatos vêm à tona de forma desordenada e Breta vai catalogando-os. Madruga, pressentindo a chegada da morte, passa a refletir acerca da oralidade e da escrita, que sempre condenava, desde quando o avô enviou-lhe uma carta de despedida, sem uma história bonita:

Sem dúvida, queria-me solto, emocionado, a expor uma matéria que lhe faltava para compreender a minha história. Uma história automaticamente empobrecida, quando contada por mim e pelos meus contemporâneos. Quem sabe, porém, não seria Breta um membro desta seita que a tudo escuta, a tudo observa, a tudo regenera, com o propósito de preservar e refazer a realidade através da escrita? (PIÑON, 2005, p. 329)

Aquela carta, em visível tom de despedida, desesperou Madruga. Não aceitava o avô partir sem lhe contar, por escrito, outras histórias. Ainda que sob o risco de ganharem elas, nas cartas, uma interpretação contrária à vontade de Xan. Pois não se sabia, então, que os livros, embora coincidentes às vezes com a realidade, em geral discordavam delas? Insistiu com o avô que lhe escrevesse, ao menos cinco linhas. A estas únicas linhas, ele saberia adicionar farinha, água e ovos. Exaurindo-se Madruga na tarefa de fazer Xan compreender que, mesmo depois de sua morte, manteria sempre viva a sua memória." (idem, p. 444)

Confiante na neta, Madruga conta-lhe, além das histórias, os seus segredos também. Por isso, leva-a à Galícia para mostrar o cenário de sua infância e coloca-a a par de um jogo que fez consigo mesmo: na casa do avô Xan, preservada por ele, havia uma cavaca entre as pedras da lareira. Aquele ato era um pacto, enquanto a madeira resistisse, escondida naquele local, seu coração ainda estaria batendo, mesmo em terras distantes, no Brasil: "a cavaca era símbolo da minha vida" (PIÑON, 2005, p. 332), o que tornava "Breta herdeira aflita do meu segredo e do meu império humano" (idem, p. 333). Jogo parecido fizera Xan a Madruga quando disse que sua melhor história não havia sido contada pois era um segredo. E assim prendia a atenção e a curiosidade do neto até seus últimos dias. Durante toda narrativa, há um jogo de despedida/morte e preocupação pela continuidade das narrações:

Lembro-me de ter escrito ao pai: "será que o avô, levado apenas por esta expectativa, desperdiçou anos de sua vida a contar-me histórias? Neste caso, terá ele pensado que eu ficaria o resto da vida em Sobreira, a ouvi-lo, enquanto a vida lá no Brasil se esgotasse? (...) Mas para mim, pai, pior que não ter estado presente ao enterro do avô Xan foi a descoberta de que me falta o dom de levar adiante os enredos que ele me ensinou. E me falta a garantia de que, no futuro, quando me case, algum filho possa herdar esta suculenta herança.” ( PIÑON, 2005, p. 546)

Vai ver, ela [a morte] queria simplesmente ouvir as minhas histórias! (...) Com este Madruga, não podemos mesmo contar. Assim sendo, a nossa família vai perder seu último narrador. (idem, p. 547)

Há que escolher, meu neto, entre a liberdade de conta e fidelidade ao ouro. (...) Estava certo de um dia retomar o hábito de Xan, este de entreter as pessoas com infindáveis histórias. Quem sabe seria no futuro um Xan redivivo, apesar do ouro a lhe refulgir no rosto. Afinal, por que deveria o narrador revestir-se do manto da miséria, do falso apanágio da modéstia, só para assegurar-se credibilidade? Mas que independência haveria de alcançar este contador, se dependesse do prato de comida daqueles que o ouviam? De um vizinho ou de uma autoridade, dispostos a podar-lhe a história, inconformados com o rumo que vinha ela tomando? (idem, p. 582-3) 
O mesmo jogo de vida e morte ocorre em VD, uma vez que Scherezade se lançou na missão de narrar para preservar a vida sob o manto da morte a rondar-lhe os aposentos. Ao passar pelo cadafalso ou saber da presença do carrasco???? Na porta de seus aposentos a aguardar a ordem do enforcamento, mais intensa se tornava a ênfase de aparente veracidade como contava suas histórias. Trata-se de um jogo de sobrevivência que opõe o dia à noite. $\mathrm{O}$ primeiro significa a vida e o segundo, a morte. Cabe somente a ela fazer com que os perigos da noite não ameacem sua vida e que as mulheres possam casar e dormir o sono tranqüilo da noite sem a ameaça da punição. O sexo transforma igualmente a passagem da noite para o dia refletindo os perigos, pela entrega. Desta forma, a mulher poderia ser punida ou salva para viver o dia seguinte e aguardar a próxima noite e suas possibilidades de novamente sobreviver, num círculo interminável de expectativas e forças renovadas:

Cercada pela pequena tribo de mulheres, Scherezade repassa na memória a simbologia da noite, amedrontadora e poética. (...) Um legado originário de ancestrais amedrontados ao primeiro sinal do crepúsculo, para quem o alvorecer era benfazejo.

A noite sempre dera início aos tormentos de Scherezade. O embate travado entre a noite e o dia, ambos com exaltada carga de contradições, imolava os seres. (...)

Mas antes mesmo que o anjo da morte a leve, Scherezade começa uma nova história. (PIÑON, 2006, p. 319)

Scherezade sabia que encarnava o modo de vida de Fátima, vivia repetindo situações e gestos inspirada no modo de ser dessa mulher que tanto lhe ensinara. E tais ensinamentos acabaram sendo passados adiante, mesmo sem ter esta intenção, para a irmã Dinazarda. O ofício de contadora salvara as mulheres do palácio e também acabara por realizar o sonho da irmã, grande parte vivido por Scherezade, porém apenas por necessidade. Diferentemente de Madruga, que vivia atormentado com a incapacidade de ser igual ao avô, seu dilema era executar o que o avô pregava quanto a ganhar "a América" ou apenas segui-lo como contador de histórias. Ora, se o avô contava histórias desejoso de vivê-las também, ele poderia fazer as duas coisas. E, ao perceber que os filhos não dariam continuidade a sua atividade, dedicou-se à neta que estava receptiva a aceitar a incumbência - mesmo que substituísse a oralidade pela escrita. Assim, tentava apaziguar seu espírito para morrer em paz. Ao pedir ao avô que lhe contasse uma história, Madruga parecia voltar de uma espécie de transe, em que se fundia à imagem e atitudes de Xan. Como Scherezade, ele lança o desafio à neta: “- Começaremos uma história agora mesmo, e sem prazo de terminar. Você promete me ouvir até o fim da minha vida? “(PIÑON, 2005, p. 585). Ao contrário de Madruga, que se preocupava em contar histórias, Eulália, sua esposa, guardou vários objetos em caixas, uma para cada filho. No seu leito de morte, entregou cada uma a seu dono para que tivessem a memória de suas 
vidas. Eulália, submissa, guardava em segredo objetos minúsculos, peculiares a cada filho. Ou seria Eulália outro tipo de narrador que cata sucata e lixo como em Baudelaire? (GAGNEBIN, 2006, p. 53). Madruga esbravejava e falava muito. Ela, com sua caixa de Pandora, aberta na despedida da vida, fazendo com que cada um se reconheça, e Madruga, com a morte anunciada (seria mais uma história?!) após preparar a neta e contar-lhe tudo que sabia sobre a família.

Ao final do livro, Madruga sente-se derrotado porque não pôde ser igual a Xan. Restalhe a esperança de que Breta consiga passar adiante a história da família. Para ele, era importante integrar a família, entrelaçando as pessoas pelas histórias, dando sentido ao grupo familiar. À história de imigrantes espanhóis que vieram para o Brasil para iniciar uma nova etapa da família, importava estar em relação com diversas coletividades, por referência às quais se define a sua identidade de classe no sentido lógico do termo - pertencer a uma pátria, a um segmento de linhagem, a uma faixa etária, a um clã, a uma aldeia, a uma nação, etc., no dizer de AUGE (1999). Fica evidente a diferença entre Madruga, Xan e Breta, tanto quanto diferenciam-se o escritor e o contador, conforme Fernandes:

O escritor dá uma outra dimensão aos fatos cotidianos e sentimentos, torna-os pungentes, reelabora-os, fixando-os no tempo com a palavra impressa. O contador, por sua vez, consome os momentos, cada fato vivido é uma aventura que ele pode compartilhar nas suas rodas de conversa. (...) é por isso que a literatura tem duas trilhas: uma da fixação e outra da dinamicidade. A que segue a primeira é canônica e escrita e a segunda, tradicional e popular. (AUGE, 2002, p. 13)

O desfecho da narrativa sela esta diferença. A história da família está garantida, porém não da maneira como Madruga e Xan gostariam:

Ao me ver, Madruga sorri com indisfarçável ansiedade. Logo, porém, acalma-se. A vida já não o comove. Mais discreto, Venâncio agradece a gentileza. Sento-me com eles. Não sei por quanto tempo. Apenas sei que amanhã começarei a escrever a história de Madruga. (PIÑON, 2005, p. 748)

O final de VD evidencia, ao contrário de RS, a continuação da oralidade sem ser questionada. A continuação de existência de contadores é que garante a perpetuação do povo árabe e seus feitos heróicos. Todas as histórias contadas por Scherezade, por fim, trouxeram ensinamentos ao Califa, visto que, suas sutis reflexões faziam com que ele entendesse o modo de ser governante. Muitas situações narradas nas histórias eram simplesmente paráfrases de situações reais, em geral, vividas ali mesmo no palácio. Instaura-se uma nova era de vida sem ameaças no califado:

... não lhe poderiam negar que fora ele quem obrigara Scherezade a contar as melhores histórias do reino, a fim de salvar-se. Graças à sua tirania, responsável por um fato 
inicialmente desonroso, a história do seu povo se consagraria para sempre. Uma edificação verbal mais poderosa que qualquer mesquita ou palácio erigidos com pedra, cal e suor. $\mathrm{O}$ que Scherezade semeara nos aposentos, através dele, nunca se apagaria. Para isto, Jasmine e Dinazarda, discípulas suas, repetiriam cada relato à exaustão. Nem elas, nem seus sucessores, deixariam morrer a substância da alma árabe. Ainda que ele e as jovens nunca mais ouvissem dos lábios de Scherezade as novas histórias que ela estaria agora contando a Fátima, que a recebera de braços abertos tão logo chegou à casa, poeirenta, faminta, mas feliz. (PIÑNON, 2006, p.351)

As histórias contadas nestes dois romances levam à ratificação da preservação cultural. Seja pela escrita, seja pela oralidade, ambos tomam a natureza das histórias, assim como a vivacidade do contador, como eixo central e vital da própria narrativa. Embora os romances aqui analisados distanciem vinte anos de publicação, ocorre a ratificação da vitalidade da contação de histórias e da perpetuação do ato narrativo nas mais variadas situações.

\section{Referências}

AUGÉ, Marc. O sentido dos outros. Petrópolis: Vozes, 1999. Tradução de Francisco Manoel Filho.

BACHELARD, Gaston. A poética do devaneio. São Paulo: Martins Fontes, 1988.

BENJAMIN, Walter. Obras Escolhidas Volume 1: Magia e técnica, arte e política. 4 ed. São Paulo: Brasiliense, 1985.

BERND, Zilá (org.). Dicionário de figuras e mitos literários das Américas. Porto Alegre: Tomo Editorial/Editora da Universidade, 2007.

FERNANDES, Frederico Augusto Garcia. Entre histórias e tererés: o ouvir da literatura pantaneira. São Paulo: UNESP, 2002.

FERNANDES, Frederico Augusto Garcia (org.). Oralidade e literatura: manifestações e abordagens no Brasil. Londrina: Eduel, 2003.

FOUCAULT, Michel. A ordem do discurso. Tradução de Laura Fraga de A Sampaio. 14 ed. São Paulo: Loyola, 2006.

FRYE, Northrop. Fábulas de identidade: ensaios sobre mitopoética. Tradução de Sandra Vasconcelos. São Paulo: Nova Alexandria, 2000.

GAGNEBIN, Jeanne Marie. Lembrar, escrever, esquecer. São Paulo: Editora 34, 2006.

HAVELOCK, Eric A. A musa aprende a escrever - reflexões sobre a oralidade e a literacia da antiguidade ao presente. Lisboa: Gradiva, 1996.

LIMA, Nei Clara de. Narrativas orais: uma poética da vida social. Brasília: Editora Universidade de Brasília, 2003. 
PIÑON, Nélida. A república dos sonhos. 5 ed. Rio de Janeiro: Record, 2005. Vozes do deserto. 5 ed. Rio de Janeiro: Record, 2006.

RICOUER, Paul. Tempo e narrativa. Vol. III. Campinas: Papirus, 1997.

ZUMTHOR, Paul. Performance, recepção, leitura. São Paulo: Educ, 2000. 